\section{Supported Systems}

Java 1.6 (Version 6, latest update). To verify your Java version, go to www.java.com and click "Do I have Java?". The following systems include support for Java 1.6 and higher:

Microsoft Windows XP, Vista, 7, and Server, 32-bit and 64-bit

- Internet Explorer 7+ (IE 8+ on Windows 7 or Windows Server 2008)

- Internet Explorer 8 go to www.java.com and click "Do I have Java?" to verify that the latest version of Java is installed

- Firefox $2+$

Apple Macintosh OS X 10.5+ (Intel)

- For more information on Java for Mac OS X, please see www.apple.com

Linux

- Firefox $2+$ or $3+$

- Mozilla 1.4.x, 1.7+

Solaris Sparc, $\mathrm{x} 86$

- Firefox $2+$ or $3+$

- Mozilla 1.4.x, 1.7+

\section{How do I install the Java plug-in?}

Download the Java plug-in for most operating systems and browsers from www.java.com. On that page, follow the Download link to get instructions for downloading and installing the plug-in for your operating system and browser.

Apple Macintosh users should go to the Downloads area of www.apple.com.
How do I get help to configure my browser?

Please refer to your browser help for information on properly configuring Java and JavaScript support. The www.microsoft.com site may be useful for information about Microsoft Internet Explorer and the www.mozilla.com site may be useful for information about Firefox.

\section{Who do I contact for assistance with GloVis?}

Please contact Customer Services at: Ita@usgs.gov

\section{USGS}

Earth Resources Observation and Science (EROS) Center 47914 252nd Street

Sioux Falls, SD 57198

Phone: 605-594-6151

FAX: $\quad 605-594-6589$

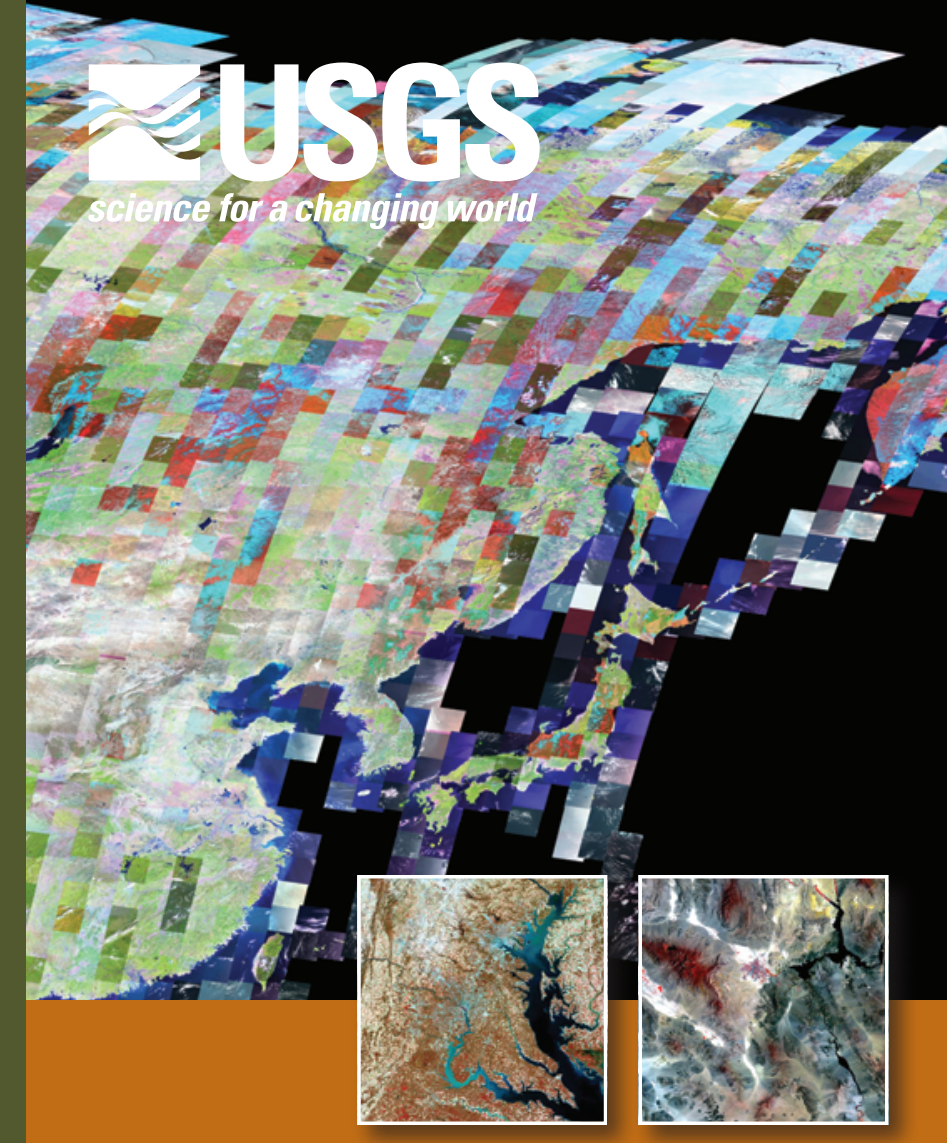

\section{GloVis}

\section{Access to Selected Land Remote Sensing Data}

http://glovis.usgs.gov

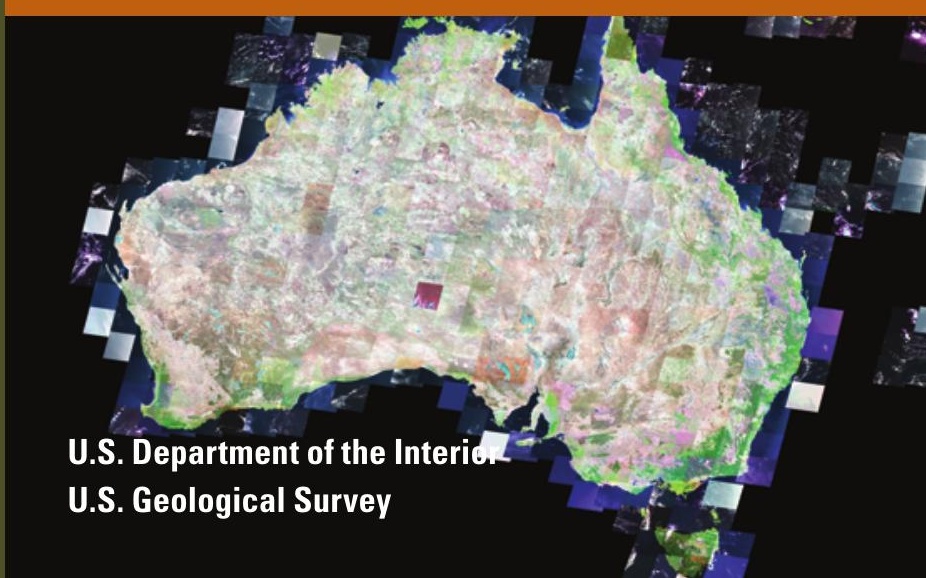




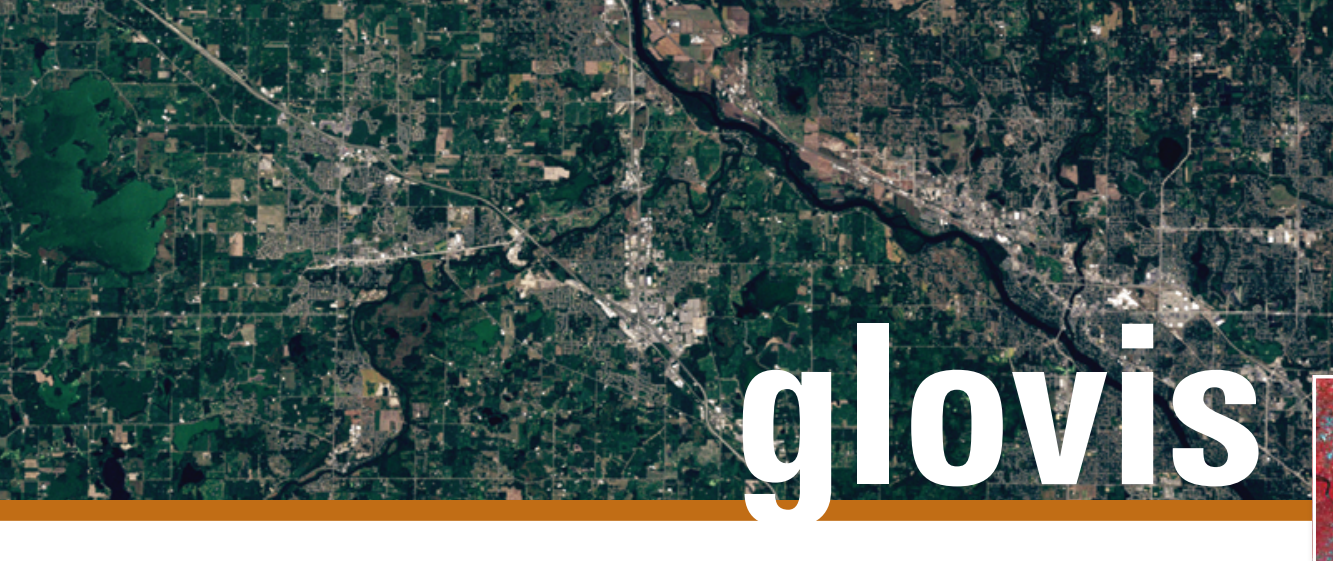

What is GloVis?

The U.S. Geological Survey (USGS) Global Visualization Viewer (GloVis) is a browser-based utility that provides easy access to a subset of aerial photography and satellite data available from the USGS/EROS archive.

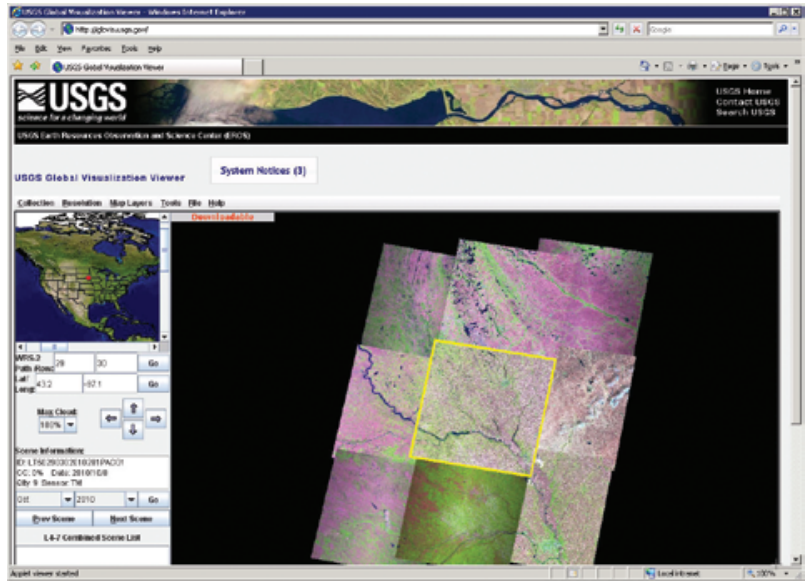

GloVis is a quick search and order tool for aerial photography and satellite data. Collections include NAPP, NHAP, ASTER, EO-1, Global Land Survey, Landsat Archive, Landsat Legacy, Landsat MRLC, MODIS Aqua, MODIS Terra, MODIS Combined, and TerraLook data sets. Through a graphic map display, a user can select an area of interest and immediately view all available browse images within the USGS inventory for a specified location. Additional features exist to optimize searches within large collections. The help menu provides user-friendly access to information about browse images, links to product information for selected collections, and a detailed user guide for all levels of users. The GloVis source code also can be downloaded and modified to support local data collections.

http://glovis.usgs.gov

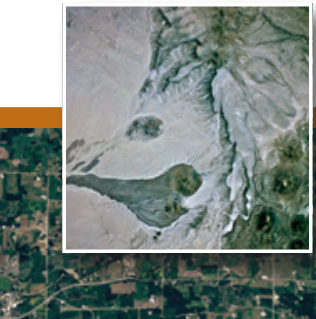

Landsat 5 Minneapolis, Minnesota September 11, 2011

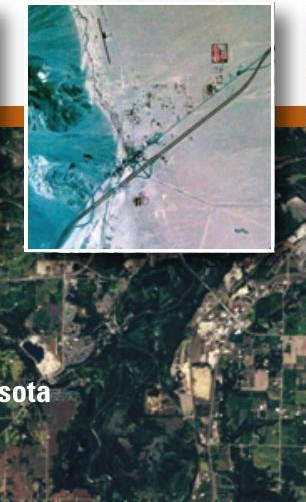

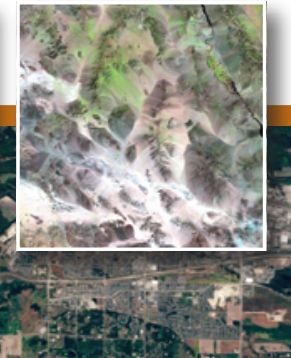

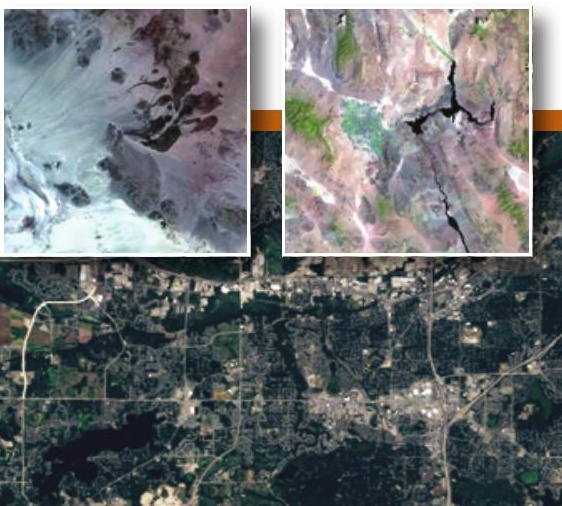

GloVis also offers features such as map layer displays, scene list maintenance, access to metadata, a download interface for data that are available at no charge, and an order interface for data that have processing options available.

\section{Browser Requirements}

GloVis is implemented as a Java applet and works either with the web browser's built-in version of Java, or with the Java plug-in.

The GloVis Viewer requires a web browser with Java 1.6 (also simply called Java 6) or newer and JavaScript. Some browsers may require the installation of a plug-in for Java.

\footnotetext{
ins have been tested. If problems are encountered, upgrading to a newer browser or installing the most recent Java plug-in may resolve the issue and improve performance.

Note: Not all combinations of operating systems, browsers, and plug-
} 